\title{
Stigmina carpophila detected on Prunus armeniaca and Prunus persica in India
}

\author{
Rafiq Ahmad Dar ${ }^{1}$ Akhila Nand Rai ${ }^{1}$ - Imtiyaz Ahmad Shiekh ${ }^{2}$
}

Received: 30 January 2017 / Accepted: 6 April 2017 /Published online: 17 April 2017

(C) Australasian Plant Pathology Society Inc. 2017

\begin{abstract}
During the late summer of 2016, a pattern of infection spots were observed in different varieties of Prunus armeniaca (Apricot) and Prunus persica (Peaches) in different locations in India. The disease led to a decline in the fruit production by almost $30 \%$ in the region. Symptomatologically, the dark brown leaf spots were hologenous, scattered over the entire surface, rounded to irregular, enlarging and coalescing, which resulted in premature defoliation. Both phenotypic \& genotypic observations were carried out by double beam Scanning Electron Microscope (SEM) and Internal Transcribed Spacer (ITS) rDNA sequencing, respectively. To our knowledge it is the first report of this disease from India and solid containment measures should be imposed to restrict its spread throughout the natural range of these ecologically, economically and historically precious hosts.
\end{abstract}

Keywords Hologenous · Sequencing · Defoliation · Scanning electron microscopy $\cdot$ Internal transcribed spacer

Akhila Nand Rai

studymycology1234@gmail.com

Rafiq Ahmad Dar

darafiq123@gmail.com

Imtiyaz Ahmad Shiekh

simi.myco@gmail.com

1 Mycology and Plant Pathology Laboratory, Department of Botany, Dr. Harisingh Gour Central University, Sagar, India

2 Mushroom Biology Laboratory, Department of Botany, Dr. Harisingh Gour Central University, Sagar, India
The genus Stigmina, consists mostly of plant pathogenic species, many attacking the fruit and foliage of economically important tree-fruit crops like Prunus armeniaca and Prunus persica. Members of the genus have singleseptate (multi-septate in rare cases) ascospores produced in ascocarps (pseudothecia) with bitunicate asci. Separation of the genus is based on phenotypic criteria and identification is aided by the narrow host specificity exhibited by each species. There have been no comparative molecular studies of the species within the genus. During the mycological explorations in June 2016 of different areas of India - $\left(33^{\circ} 44^{\prime} 44^{\prime \prime} \mathrm{N} 75^{\circ} 13^{\prime} 13^{\prime \prime} \mathrm{E} /\right.$ $33.7456817^{\circ} \mathrm{N} 75.2203792^{\circ} \mathrm{E} / 33.7456817 /$ 75.2203792) (Table 1), a pattern of dark brown leaf spots (Fig. 1) on different varieties of Prunus species were observed in considerable proportions. 39 infected isolates were collected in autoclaved polybags labeled with tags. Both infected leaf/fruit bits were inoculated directly on to the PDA growth slants and incubated at $26^{\circ} \mathrm{C}$ for 15 days. Pure homogenous cultures were obtained after a number of successful subculturing attempts (Dar et al. 2016) (deposited in University Phytopathology Unit with accession no. SU1099). To confirm the authenticity, the pathogen was reisolated from the diseased experimental host and identified as being identical to the original specific causative agent (Koch 1876). In the pathogenicity test, the spores of the fungus when sprayed on the fresh leaves/fruits caused the same symptoms in four weeks after the artificial inoculation, which were similar to observations in the field. The mean lesion lengths resulting from surface inoculation of the fungus are given in Table 2 . Different varieties responded differently, the longest lesions $($ mean $=6.028 \mathrm{~mm}$ ) were obtained from KASH1078 isolate and the shortest lesions from the 
Table 1 Sites selected and surveyed showing different percentage of Stigmina carpophila occurrence in different locations in India

\begin{tabular}{lllll}
\hline S no. & Area surveyed & $\begin{array}{l}\text { No. of plants } \\
\text { observed }\end{array}$ & $\begin{array}{l}\text { No. of plants } \\
\text { infested }\end{array}$ & $\begin{array}{l}\text { \% of fungal } \\
\text { occurrence }\end{array}$ \\
\hline 01 & Anantnag & 30 & 07 & 0.234 \\
02 & Baramulla & 35 & 11 & 0.314 \\
03 & Shopian & 37 & 14 & 0.378 \\
04 & Kupwara & 15 & 03 & 0.2 \\
05 & Srinagar & 10 & 04 & 0.4 \\
& Total & 127 & 39 & 0.307 \\
\hline
\end{tabular}

KASH1055 isolate $($ mean $=2.011 \mathrm{~mm})$. Phenotypic observations by double beam Scanning electronic microscope (FEI Nova Nano SEM- 450) (Hall \& Hawes 1991) revealed the different mycotaxonomic characters of the fungus viz. mycelium internal, conidia branched, septate and smooth, produced singly on conidiophores from fascicles projecting through the stomata. Conidiophores were straight, pale brown and somewhat bacillus shaped. Conidiogenous cells arising from the stromata, doliiform to cylindrical discrete, verrucose proliferations, integrated, scars flattened inconspicuous (Sutton and Pascoe, 1989; Crous et al. 1995). Conidia cylindrical obclavate, light to dark brown, 4-8 transverse septate, rarely with one vertical or oblique septum, smooth, apex rounded-obtuse (Fig. 2a-c \& d). Pure DNA $(50-70 \mathrm{mg})$ was obtained from 8 day old fresh cultures using CTAB method (Carlier et al. 1996). PCR reactions were carried out using forward primer ITS1 (5'-TCCGTAGGTGAACCTGCGG-3') and
Table 2 Pathogenicity study conducted on different isolates of Prunus species artificially inoculated with fungus. Different varieties respond differently (Standard mean deviation, $S d=1.083$ )

\begin{tabular}{ll}
\hline Isolate number & Mean lesion length $(\mathrm{mm})$ \\
\hline KASH1078 & 6.028 \\
KASH1099 & 5.029 \\
KASH1065 & 4.023 \\
KASH1055 & 2.011 \\
KASH1040 & 3.019 \\
\hline
\end{tabular}

reverse primer ITS4 (5'-TCCTCCGCTTATTGATATGC$3^{\prime}$ ) (White et al. 1990). Initial PCR optimisation consisted of obtaining amplification of each target gene under individual reaction conditions. In the end, each PCR reaction contained $0.2 \mathrm{mM}$ each dNTP, $1.5 \mathrm{mM}$ $\mathrm{MgCl}_{2}, 0.25 \mu \mathrm{L}$ Taq DNA polymerase, $1.0 \mu \mathrm{M}$ each forward and reverse primers, buffer and variable template concentrations. PCR was performed for 35 cycles of $96{ }^{\circ} \mathrm{C} 30 \mathrm{~s} ; 50{ }^{\circ} \mathrm{C} 15 \mathrm{~s}$; and $68{ }^{\circ} \mathrm{C} 2 \mathrm{~min}$. PCR products were separated by electrophoresis in $2 \%$ low melting point agarose and visualised by ethidium bromide staining. To confirm that the proper ribosomal sequences were being amplified each PCR product sequenced using an ABI 3100 Genetic Analyzer with the output sequences analysed for accuracy. Genetic sequencing of the amplified ribosomal sequences was carried out utilising the Big Dye Terminator system. To further investigate the relationship between our isolates with other species, we constructed the phylogenetic tree
Fig. 1 Images of the host, Prunus species, infected with Stigmina carpophila

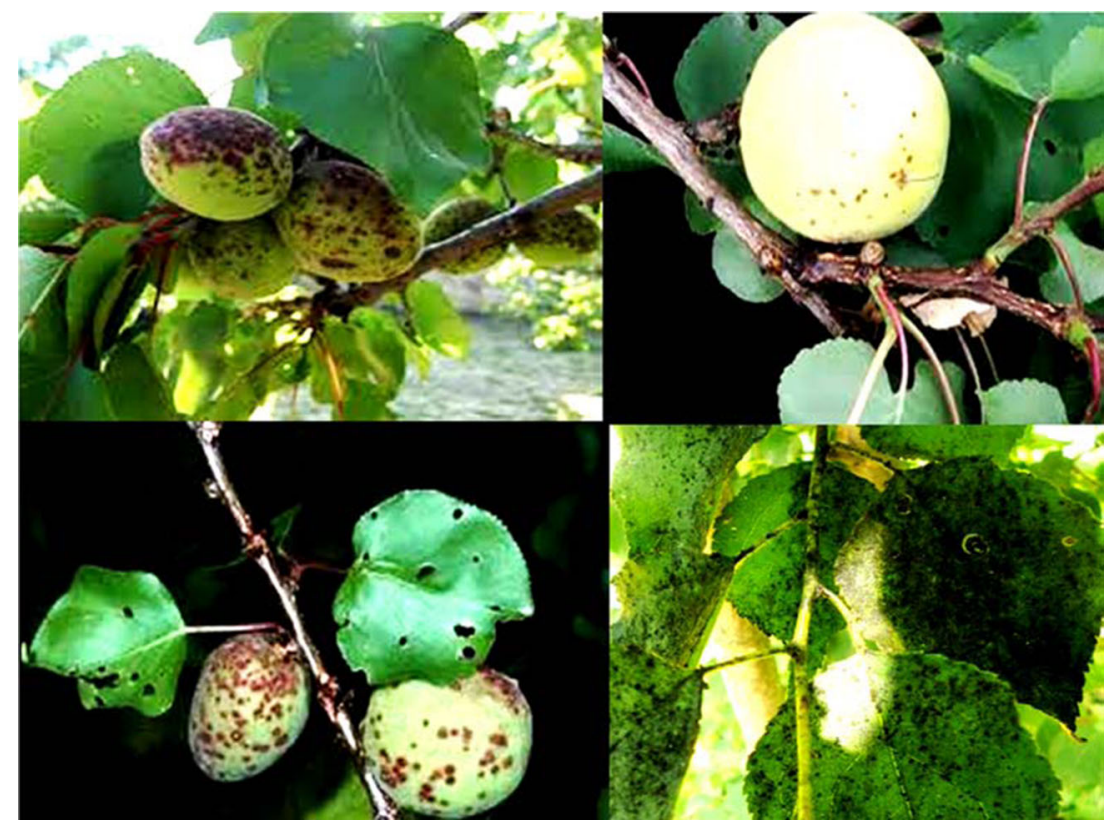


Fig. 2 SEM images of Stigmina carpophila, a conidia at $1500 \mathrm{X}$ with average length $10.41 \mu \mathrm{m}$, b host-fungus attachment at $6000 \mathrm{X}$, c average conidial diameter $2.480 \mu \mathrm{m}$ at $6000 \mathrm{X}$ and $\mathbf{d}$ conidial bursting at $12000 \mathrm{X}$
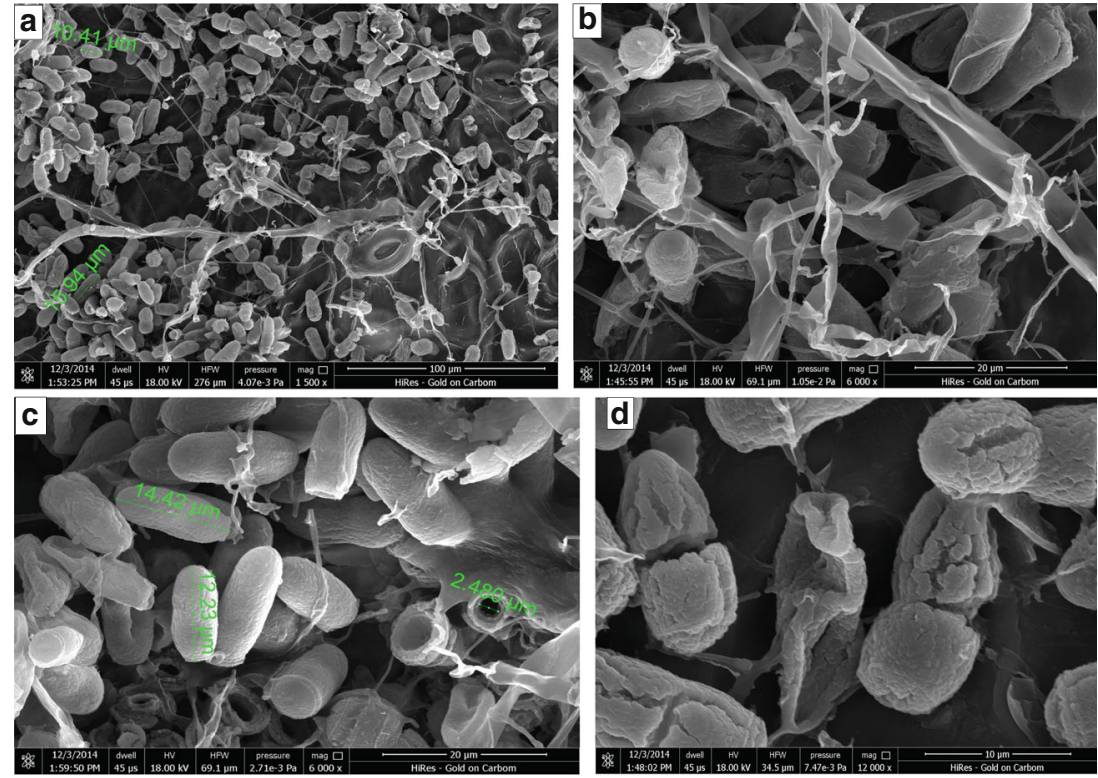

using the UPMGMA (Unweighted Pair Group Method with Arithmetic Mean) clustering method (Fig. 3). A total of 1000 bootstrap replications were conducted with each method to determine the statistical significance of the obtained branches. The nucleotide sequences have been deposited in NCBI GenBank. The results were compared with the NCBI-BLAST (http://www.ncbi.nlm.

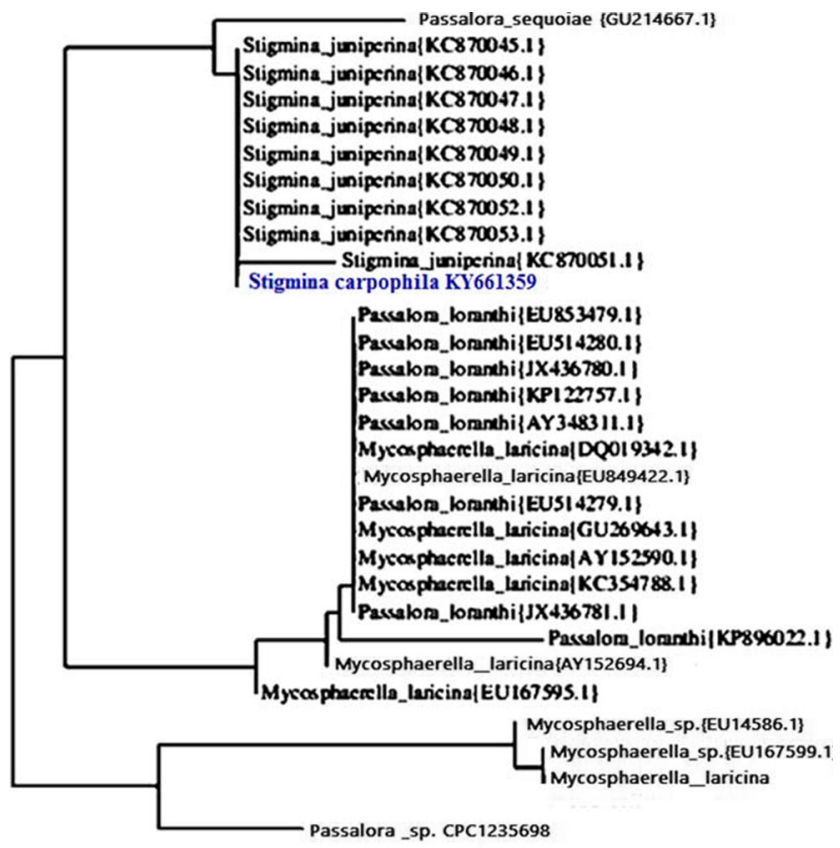

$0.4 \%$ divergence

Fig. 3 Maximum likelihood phylogenetic tree based on (SSU-ITS-LSU) rDNA sequence variants of the Stigmina carpophila with the closely related sequence matches constructed by UPMGMA. Bootstrap values are given for branches nih.gov/) databases. The phylogenetic interpretations revealed ample amounts of genetic divergences probably due to the persistent extreme environmental conditions in the surveyed area. As these tree species are deciduous, the fungal populations may have encountered extreme variation in environmental conditions (prolonged chilly snow periods viz. the disease became increasingly severe with fall in temperature from November to January given in Fig. 4), which might have resulted in variations of fungus genotype as well as phenotype. Stigmina carpophila isolate has diverged from closely related Stigmina juniperina (KC870051.1) by $0.4 \%$ under geography diverse environments. The NCBI GenBank accession number for the ITS gene sequence, amplified with primers ITS1 and ITS4 from isolate no. 660a (NCBI unique submission Id BankIt1995376), assigned as KY661359.

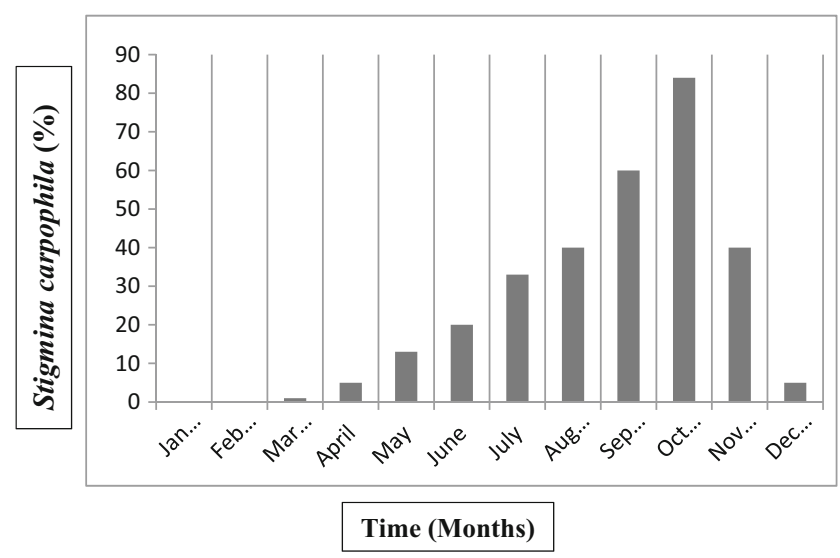

Fig. 4 Magnitude of Stigmina carpophila occurrence and extent of its infection changes parabolically with the fluctuating environmental conditions in different seasons in the prevailing area 


\section{References}

Carlier G, Lorand JP, Bonhomme M, Carlotto V (1996) A reappraisal of the Cenozoic inner arc magmatism in southern Peru: consequences for the evolution of the Central Andes for the past 50 ma. Third ISAG St Malo, France, extended abstracts. Pp 551-554

Crous PW, Lennox CL, Sutton BC (1995) Selenophoma eucalypti and Stigmina robbenensis sp. nov. from eucalyptus leaves on Robben Island. Mycol Res 99(6):648-652. doi:10.1016/S0953-7562(09) 80521-2

Dar RA, Rai AN, Shiekh IA (2016) First report of white stain of apple caused by Trichothecium kashmeriana in India. Arch Phytopathol plant protect 1-10. doi10.1080/03235408.2016.1264178
Hall JL, Hawes CH (1991) Electron microscopy of plant cells. Academic Press, New York

Koch R (1876) Studies on bacteria V. The etiology of anthrax disease, based on the developmental history of Bacillus anthracis. Biol D plants 2:277-310. Milestones in microbiology 1556

Sutton BC, Pascoe IG (1989) Reassessment of Peltosoma. Stigmina and Batcheloromyces and description of Hyphothyrium gen nov Mycological Research 92(2):210-222. doi:10.1016/S09537562(89)80013-9

White T, Bruns T, Lee S, Taylor J (1990) Amplification and direct sequencing of fungal ribosomal RNA genes for phylogenetics. P 315 322 